\title{
AVALIAÇÃO DAS CARACTERÍSTICAS GERMINATIVAS E DE CRESCIMENTO EM MAMONEIRA CULTIVADA EM DIFERENTES RESÍDUOS ORGÂNICOS AGROINDUSTRIAIS
}

\author{
F.A.GONDIM", F.B.B.ALMEIDA, L.F.MOURA, F.R.S.COSTA, J.F.ARRUDA, L.M. SENA \\ Instituto Federal de Educação, Ciência e Tecnologia do Ceará \\ aragaofg@yahoo.com.br*
}

Artigo submetido em 02/08/2018 e aceito em 20/11/2019

DOI: $10.15628 /$ holos.2019.7572

\begin{abstract}
RESUMO
A mamona é uma oleaginosa bastante utilizada para a fabricação de biocombustível. O objetivo deste trabalho foi avaliar as variáveis germinativas e de crescimento em plântulas de mamona cultivadas em diferentes resíduos orgânicos agroindustriais. O experimento foi conduzido em casa de vegetação no IFCE Campus Maracanaú em delineamento experimental inteiramente casualizado com 7 tratamentos (1. 100\% de areia em volume; $50 \%$ de areia e 50\% de resíduos orgânicos agroindustriais: 2 . húmus de minhoca; 3 . casca de amendoim; 4. fibra de coco; 5 . bagaço de cana, 6 . torta de mamona; ou 7 . casca de arroz carbonizada) e 5 repetições. Inicialmente foram analisadas as variáveis germinativas (Percentual de emergência, Índice de velocidade de emergência e tempo médio de germinação). Em seguida, aos 9 dias após semeadura (DAS), foram avaliados semanalmente as
\end{abstract}

variáveis de crescimento (altura, diâmetro do coleto e o número de folhas). Aos 28 DAS foram aferidos os teores relativos de clorofila e realizada a coleta das plântulas para quantificar a matéria fresca, seca e área foliar. A torta de mamona e casca de arroz carbonizada não podem ser utilizados na formulação de substratos, pois impossibilitaram a germinação. A fibra de coco e bagaço de cana de açúcar possibilitaram a germinação, porém com reduzido crescimento das plântulas. Dentre os resíduos agroindustriais, a casca de amendoim apresentou os melhores resultados. Devido ao reduzido custo e fornecer uma destinação adequada ao resíduo, o uso da casca de amendoim poderia ser uma alternativa orgânica para o cultivo de mamona, visto ser uma estratégia viável e ambientalmente vantajosa.

PALAVRAS-CHAVE: Análise de crescimento, Resíduos agroindustriais, Ricinus communis.

\section{EVALUATION OF GERM AND GROWTH CHARACTERISTICS IN CASTOR BEAN CULTIVARED UNDER DIFFERENT ORGANIC AGROINDUSTRIAL WASTE}

\begin{abstract}
Castor oil is oil used in the manufacture of biofuel. The objective of this work was to evaluate germination and growth variables in castor bean plants grown in different agroindustrial organic residues. The experiment was conducted under greenhouse conditions at IFCE Campus Maracanaú in a completely randomized experimental design with 7 treatments (1. 100\% sand in volume, 50\% sand and $50 \%$ organic agroindustrial waste: 2 . earthworm humus; peanut shell, coconut fiber, 5 . sugarcane bagasse, castor oil cake, or carbonized rice husk) and 5 replicates. Initially the germination variables were analyzed (Emergency percentage, Emergency speed index and average germination time). Then, at 9 days after sowing (DAS), the growth variables (height, collection diameter
\end{abstract}

and number of leaves) were evaluated weekly. At 28 DAS the relative levels of chlorophyll were measured and the seedlings collected to quantify fresh matter, dry matter and leaf area. The castor cake residue and charcoal rice husk cannot be used in the formulation of substrates, since they prevented the germination. Coconut fiber and sugarcane bagasse allowed the germination, but with reduced growth of the seedlings. Among the agroindustrial residues, the peanut shell presented the best results. Due to the low cost and adequate disposal of the residue, peanut bark could be an organic alternative to castor bean cultivation, since it is a viable and environmentally advantageous strategy.

KEYWORDS: Growth analysis, Agroindustrial waste, Ricinus communis. 


\section{INTRODUÇÃO}

O esgotamento das reservas de combustíveis fósseis associado aos impacto ambientais tem evidenciado a busca por fontes energéticas menos poluentes e renováveis. Deste modo, verifica-se a ascensão dos biocombustíveis no cenário nacional frente aos combustíveis fosseis. Dentre estes combustíveis renováveis destaca-se o biodiesel, que é oriundo de vegetais oleaginosos. No Brasil o óleo extraído da mamona é uma alternativa à produção deste combustível, desta forma criou-se uma perspectiva real para a expansão do cultivo da mamona (LIRA e BARRETO, 2009).

A Mamona é uma espécie bastante exigente em nutrientes, desta forma é considerada esgotadora de solos, tendo produtividade muito alta em solos com alta fertilidade natural ou que receberam adubação em quantidade adequada (SEVERINO et al., 2006). Desta maneira, seu cultivo se tornaria incompatível com solos do semiárido, pois são solos rasos e com baixa disponibilidade nutricional.

Normalmente, para o enriquecimento deste solo são empregados substratos comerciais, porém, estes acarretam elevados custos de produção (DANNER et al., 2007). Assim, pensou-se então, na utilização de um meio alternativo, como a utilização dos resíduos sólidos provenientes dos processos agroindustriais (MALHEIROS e PAULA JÚNIOR, 1997).

A utilização de compostos orgânicos na fabricação desses substratos é uma alternativa viável tanto do ponto de vista econômico, como ambiental. Isso ocorre em razão a estes compostos proporcionarem uma redução dos custos de produção, ciclagem de nutrientes e disposição adequada dos resíduos no ambiente (HIGASHIKAWA, 2013).

Entre materiais frequentemente utilizados como substrato, cita-se: esterco bovino (CAVALCANTI et al., 2002), bagaço de cana (MELO et al., 2003), mucilagem de sisal, casca de amendoim e cama de frango (LIMA et al., 2006). Contudo a qualidade física e química dos substratos influencia o processo de germinação das sementes, especialmente com relação ao desenvolvimento radicular (TORRES et al., 2012).

Diante do exposto, buscou-se encontrar resultados positivos que viabilizem a germinação e o crescimento da mamona em substratos alternativos. Desta forma, objetivou-se com este trabalho avaliar a germinação e o crescimento em mamoneira BRS Energia, cultivada em diferentes substratos orgânicos (resíduos agroindustriais).

\section{MATERIAL E MÉTODOS}

O experimento foi conduzido em casa de vegetação localizada no IFCE Campus MaracanaúCE, Brasil no período de agosto a setembro de 2016. Os valores médios de umidade relativa do ar e temperatura foram $54 \%$ e $31 \stackrel{\circ}{\circ}$, respectivamente. Inicialmente, foram semeadas 5 sementes por vaso a fim de avaliar as variáveis germinativas. Em seguida, aos 9 dias após a semeadura (DAS), realizou-se desbaste e adotou-se o delineamento experimental inteiramente casualizado (DIC), com 7 tratamentos e 5 repetições com 3 plântulas. Cada tratamento foi composto por uma mistura em 
partes iguais (em volume) de areia e resíduos orgânicos agroindustriais: húmus de minhoca (controle positivo), casca de amendoim, fibra de coco, bagaço de cana, torta de mamona ou casca de arroz carbonizada (Tabela 1).

Tabela 1. Concentrações de Nitrogênio total ( $\mathrm{N}$ total), fósforo total ( $\mathrm{P}$ total), potássio $\left(\mathrm{K}^{+}\right)$, cálcio (Ca ${ }^{2}$ e magnésio $\left(\mathrm{Mg}^{2+}\right)$ dos resíduos agroindustriais utilizados na preparação dos substratos para o cultivo da mamona.

\begin{tabular}{llllll}
\hline Substrato & $\mathrm{N}$ total & $\mathrm{P}$ total & $\mathrm{K}^{+}$ & $\mathrm{Ca}^{2+}$ & $\mathrm{Mg}^{+2}$ \\
\hline & - & & & & \\
Húmus de minhoca & 15 & 13 & 17,0 & 14,0 & 5,0 \\
Casca de amendoim & 9,7 & 0,2 & 1,7 & 4,5 & 3,3 \\
Fibra de coco & 9,5 & 2,7 & 21,4 & 6,1 & 2,5 \\
Bagaço de cana & 10,7 & 2,5 & 9,4 & 0,7 & 0,4 \\
Torta de mamona & 75,4 & 31,1 & 6,6 & 7,5 & 5,1 \\
Casca de arroz & 7,0 & 2,0 & 3,2 & 8,4 & 22,3 \\
\hline
\end{tabular}

Foram utilizadas sementes de mamona cultivar BRS Energia cedidas pela EMBRAPA algodão (em abril de 2016). A semeadura ocorreu em vasos plásticos de 5 litros. Realizou-se a rega diária a $80 \%$ da capacidade de campo de cada substrato, por um período de 28 dias. Foram avaliados as seguintes variáveis germinativas: Índice de velocidade de emergência (IVE), calculado pelo somatório do número de sementes germinadas a cada dia, dividido pelo número de dias decorridos entre a semeadura e a germinação (MAGUIRE, 1962); Tempo médio de germinação (TMG), obtido através de contagens diárias das sementes germinadas até oito dias após a semeadura (DAS), sendo expresso em dias (LABORIAU, 1983), e o percentual de emergência (\%E), que se constituiu da percentagem de sementes germinadas.

Após a emergência das plântulas (9 DAS), foram registrados semanalmente os valores de crescimento em altura da planta e diâmetro caulinar, com o auxílio de um paquímetro digital e o número de folhas, no período de 9 a 28 dias após a semeadura (DAS). Na última avaliação, aos 28 DAS, determinaram-se os teores relativos de clorofila com um medidor portátil - Minolta SPAD 502, Osaka, Japão.

Os dados de massa fresca da parte aérea e das raízes e, a área foliar foram aferidos por meio de um scanner foliar. O material obtido na coleta foi colocado em estufa com circulação forçada de ar a 60 ㄷ para as determinações das massas secas da parte aérea e raízes.

Ao fim da fase de cultivo das plantas, foram determinados o $\mathrm{pH}$ e a condutividade elétrica dos extratos de saturação dos substratos para verificar a presença de sais dissolvidos em excesso. Amostras homogêneas de cada um dos substratos foram dispostas em água destilada na proporção de 2:1 (em volume). Após $48 \mathrm{~h}$ foram realizadas as medições utilizando um medidor de $\mathrm{pH}$ digital e um condutivímetro.

Os dados de altura da parte aérea, número de folhas e diâmetro dos caules foram submetidos à análise de variância (ANOVA) e regressão polinomial utilizando-se o programa estatístico Sisvar 5.4 (FERREIRA, 2010). Já os dados de teores relativos de clorofila, matéria fresca e seca foram 
submetidos à análise de variância (ANOVA) e as médias comparadas pelo teste de Tukey $(P \leq 0,05)$ através do programa Sigma Plot 11.0.

Todos os dados expostos graficamente representam a media de cinco repetições mais ou menos o erro padrão.

\section{RESULTADOS E DISCUSSÕES}

Dos substratos propostos, somente cinco possibilitaram a germinação das sementes de mamona. Dados como o $\mathrm{pH}$ e a condutividade elétrica são fundamentais para o desenvolvimento das plantas, tendo em vista que inferem diretamente na absorção de nutrientes (Tabela 2).

Tabela 2. Valores de pH e condutividade elétrica dos extratos de saturação dos substratos utilizados para o cultivo da mamona ao fim do período experimental.

\begin{tabular}{lcc}
\hline \multicolumn{1}{c}{ Substratos } & $\mathrm{pH}$ & Condutividade elétrica $\left(\mathrm{dS} . \mathrm{m}^{-1}\right)$ \\
\hline Areia & 7,29 & 0,135 \\
Húmus + areia & 7,71 & 0,389 \\
Amendoim + areia & 6,95 & 0,316 \\
Fibra de coco + areia & 6,99 & 0,257 \\
Bagaço de cana + areia & 5,74 & 0,593 \\
Torta de mamona + areia & 7,07 & 1,270 \\
Casca de arroz carbonizada + areia & 4,80 & 0,968 \\
\hline
\end{tabular}

$\mathrm{O}$ pH é um fator que pode influenciar na germinação e no crescimento da radícula. $\mathrm{O}$ efeito direto o $\mathrm{pH}$ resulta da ação dos íons $\mathrm{H}^{+}$ou $\mathrm{OH}^{-}$sobre as membranas das células das raízes. Em $\mathrm{pH}$ inferior a 4,0, a elevada concentração hidrogeniônica afeta a integridade e permeabilidade das membranas, podendo haver perda de nutrientes já absorvidos. (ANDRADE NETO et al., 2002). Já em $\mathrm{pH}$ superior a 6,5, podem ocorrer precipitações de elementos como cálcio, fósforo, ferro e manganês, que se tornam indisponíveis às plantas (MARTINEZ, 2002)

A condutividade elétrica aparente do solo é influenciada por uma combinação de propriedades físico-químicas incluindo sais solúveis, teor de argila e mineralogia, teor de água no solo, densidade aparente, matéria orgânica e temperatura do solo (CORWIN et al., 2005). Pizarro (1996), afirmou que condutividades elétricas do solo superiores a $2 \mathrm{dS} . \mathrm{m}^{-1}$ podem ocasionar danos à produção de cultivares sensíveis. As mudanças na absorção de água e nutrientes, proporcionadas pela variação da condutividade do meio nutritivo, levam às alterações da fisiologia das plantas (BELTRÃO et al., 1997). Essas alterações relacionam-se, dentre outros fatores, à abertura estomática e ao aumento ou diminuição da área foliar, estando esses fatores intimamente ligados com a eficiência fotossintética, e consequentemente, com a produção de material seco pelas plantas (SILVA, 2017). Desta forma, acredita-se que estes fatores possam ter contribuído para o insucesso da germinação.

Com relação às variáveis germinativas, observou-se que, quanto ao percentual de emergência (E\%), o Húmus se mostrou o melhor tratamento seguido da casca de amendoim e do bagaço cana-de-açúcar (Figura 1A). Assim, os tratamentos Húmus e amendoim apresentaram incrementos de 60 e 47\%, respectivamente, em relação ao tratamento areia. Sabe-se que ausência 
de nutrientes no solo pode implicar diretamente no crescimento da plântula, principalmente a deficiência de nitrogênio (MENDES, 2007). Assim o E\% se correlacionou à disponibilidade de nutrientes nos substratos empregados. Adicionalmente, sugere-se que a elevada condutividade elétrica e o $\mathrm{pH}$ ácido observados no tratamento contendo bagaço de cana de açúcar possa ter contribuído para o reduzido \%E. Tendo em vista que o excesso de sais no solo pode elevar a condutividade elétrica do extrato de saturação e comprometer as razões $\mathrm{Na}^{+} / \mathrm{Ca}^{2+}, \mathrm{Na}^{+} / \mathrm{Mg}^{2+}$ e $\mathrm{Na}^{+} / \mathrm{K}^{+}$nas plantas (PEREIRA et al., 2006).

Referindo-se ao índice de velocidade de emergência (IVE) e ao tempo médio de germinação (TMG), notou-se que os maiores IVEs foram observados nos tratamentos contendo húmus e amendoim, levando a incrementos de 69 e 68\%, respectivamente, em relação ao controle negativo (areia). Estes substratos também proporcionaram os menores TMGs (Figuras 1B e 1C). Segundo Soares et al. (2012) um elevado IVE implica em um melhor desenvolvimento radicular e vegetativo pois possibilita uma maior rapidez de estabelecimento, que ocorre em função do rápido desenvolvimento da parte aérea. Este fato permite antecipar a captação dos raios solares, desencadeando os processos fisiológicos e bioquímicos da planta.
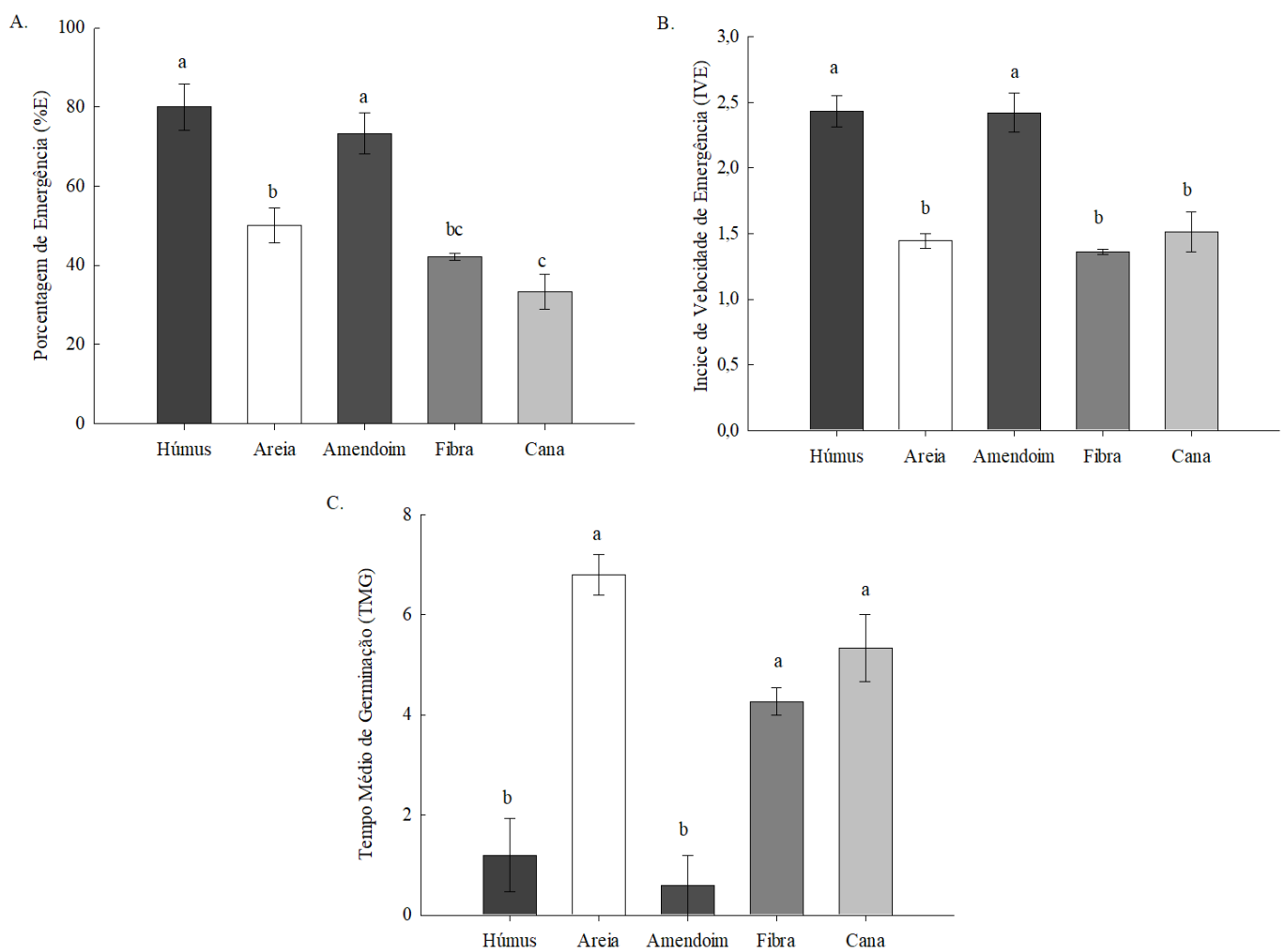

Figura 1. Percentual de emergência (A); Índice de velocidade de emergência (B); Tempo médio de germinação em plântulas de mamona $(C)$ submetidas a diferentes substratos orgânicos aos 9 dias após a semeadura. Diferentes letras indicam diferenças significativas em relação ao tipo de substrato de acordo com o teste de Tukey $(P \leq 0,05)$.

Com relação aos teores relativos de clorofila (Figura 2), os maiores valores foram observados nos tratamentos húmus, amendoim e cana de açúcar que não diferiram entre si e foram, em média, 
$48 \%$, maiores do que o tratamento contendo somente areia. Os reduzidos valores no tratamento contendo somente areia se devem à ausência de nutrientes necessários para a síntese das moléculas de clorofila que também implicou diretamente no crescimento e desenvolvimento das plântulas. A disponibilidade de nitrogênio existente na formulação mineral, refletindo em rápida absorção e reposta da planta na produção de clorofila (ALMEIDA, 2017).

As alterações nos teores relativos de clorofila podem ocasionar reduções na fotoassimilação e consequentemente no crescimento e no desenvolvimento das plantas (GODOY et al., 2008).

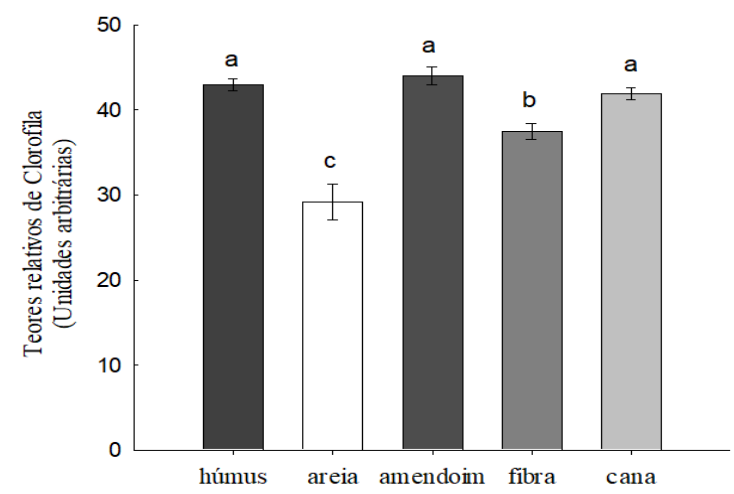

Figura 2. Teores relativos de clorofila de plântulas de mamona submetidas a diferentes substratos contendo resíduos agroindustriais aos 28 dias após a semeadura (DAS). Diferentes letras indicam diferenças significativas em relação ao tipo de substrato de acordo com o teste de Tukey $(P \leq 0,05)$.

Na Figura 3 podem ser observadas as tendências das plântulas de mamona nas variáveis altura da parte aérea (Figura 3A), número de folhas (Figura 3B) e diâmetro do coleto (Figura 3C) no decorrer do tempo. De modo geral, os tratamentos contendo o húmus e casca de amendoim, foram os que promoveram os maiores incrementos nas variáveis analisadas. Para a altura da parte aérea (Figura $3 \mathrm{~A}$ ) os tratamentos húmus, fibra, cana e areia se ajustaram a modelos lineares, enquanto a casca de amendoim ao quadrático. Para o número de folhas (Figura 3B) e diâmetro do coleto (Figura $3 \mathrm{C})$, todos os tratamentos se ajustaram a modelos lineares, excetuando-se o tratamento casca de amendoim que mostrou curva de resposta quadrática para o diâmetro do coleto.
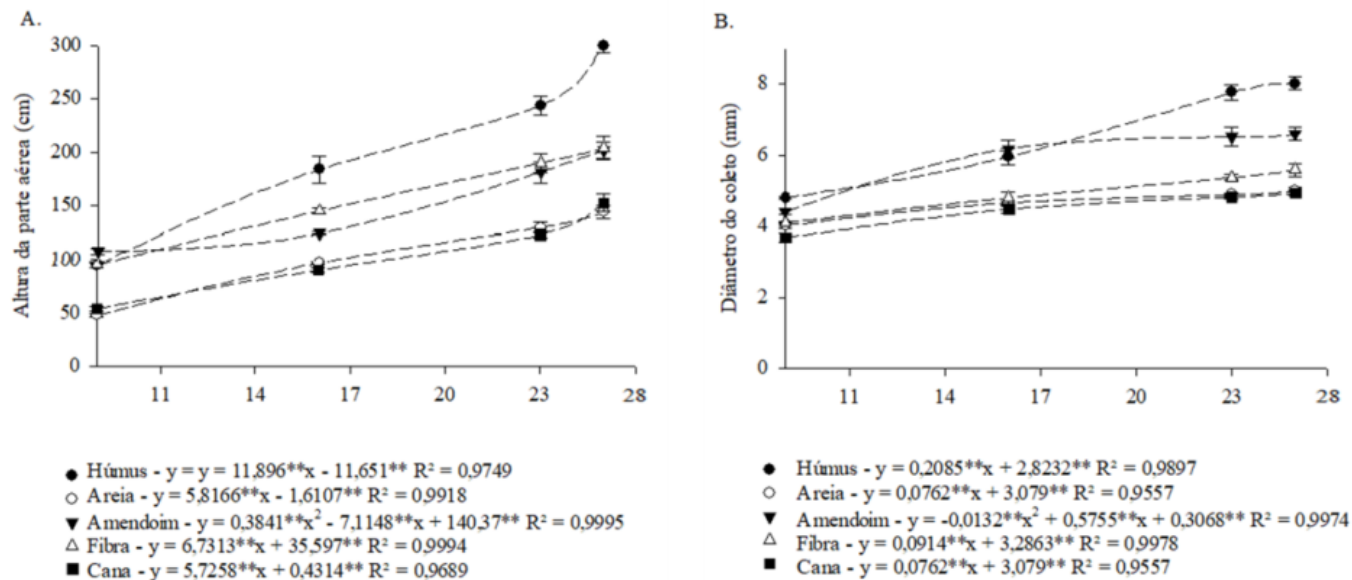


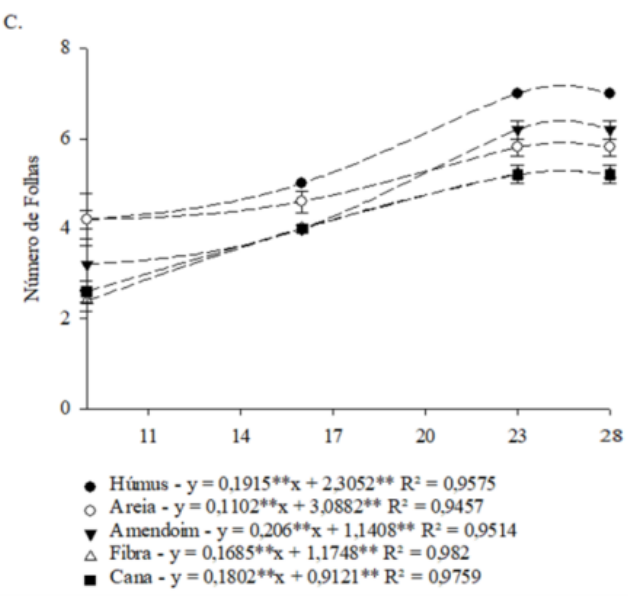

Figura 3. Altura da parte aérea (A), número de folhas (B) e Diâmetro do coleto (C) de plântulas de mamona cultivadas em diferentes resíduos agroindustriais. *Significativo a 0,01 de probabilidade; ** Significativo a 0,05 de probabilidade; ns Não Significativo.

Aos 28 DAS, com relação à altura, os tratamentos húmus e amendoim apresentaram acréscimos de 108 e 40\%, respectivamente em relação ao tratamento areia. Para o número de folhas, este incremento foi de $20 \%$ para o húmus e $7 \%$ para o amendoim. Finalmente, para o diâmetro do coleto, os acréscimos foram de $60 \%$ para o húmus e $32 \%$ para o amendoim em referência ao substrato areia.

Os substratos que ocasionaram maiores crescimentos das plântulas foram o húmus e o casca de amendoim. O húmus é um substrato conhecido na literatura para o cultivo de plantas por disponibilizar os nutrientes necessários para o crescimento e o desenvolvimento. Esses dados corroboram com os encontrados por Lima e seus colaboradores (2006), onde verificaram que a casca de amendoim e o húmus apresentam significativa quantidade de nutrientes, principalmente de nitrogênio. O nitrogênio é um dos principais macronutrientes associados ao crescimento das plantas, baixas concentrações afetam de forma direta o número de folhas, área foliar, diâmetro do coleto e a altura (SILVA et al. 2010).

Os maiores valores para a área foliar (Figura 4) foram encontrados no tratamento húmus, seguido do amendoim. O tratamento amendoim foi 196, 268 e $295 \%$ maior do que os tratamentos areia, fibra e cana, respectivamente. Segundo Monteiro et al. (2005), a área foliar é um indicador de grande importância, sendo utilizada para estimar a produtividade de um ecossistema vegetal, seu crescimento e desenvolvimento. 


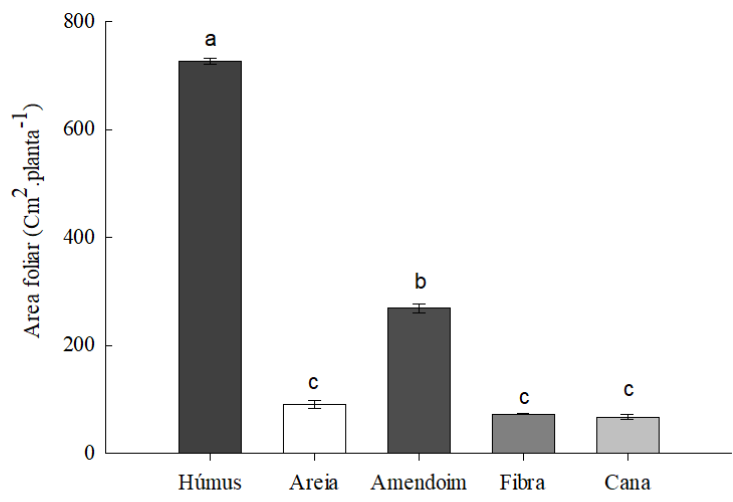

Figura 4. Área foliar de plântulas de mamona submetidas a diferentes substratos contendo resíduos agroindustriais aos 28 DAS. Diferentes letras indicam diferenças significativas ao tipo de substrato de acordo com o teste de Tukey $(P \leq 0,05)$.

Com relação às variáveis de matéria fresca da parte aérea, da raiz e total (Figura 5), os resultados foram mais elevados para os substratos que continham húmus e casca de amendoim. 0 tratamento contendo húmus apresentou um incremento para as variáveis matéria fresca da parte aérea, das raízes e total em relação ao tratamento areia de $665 \%$, 373\% e 572\%, respectivamente. Já para o tratamento amendoim os valores foram 179\%, 56\% e 149\%, respectivamente, em relação ao tratamento areia.
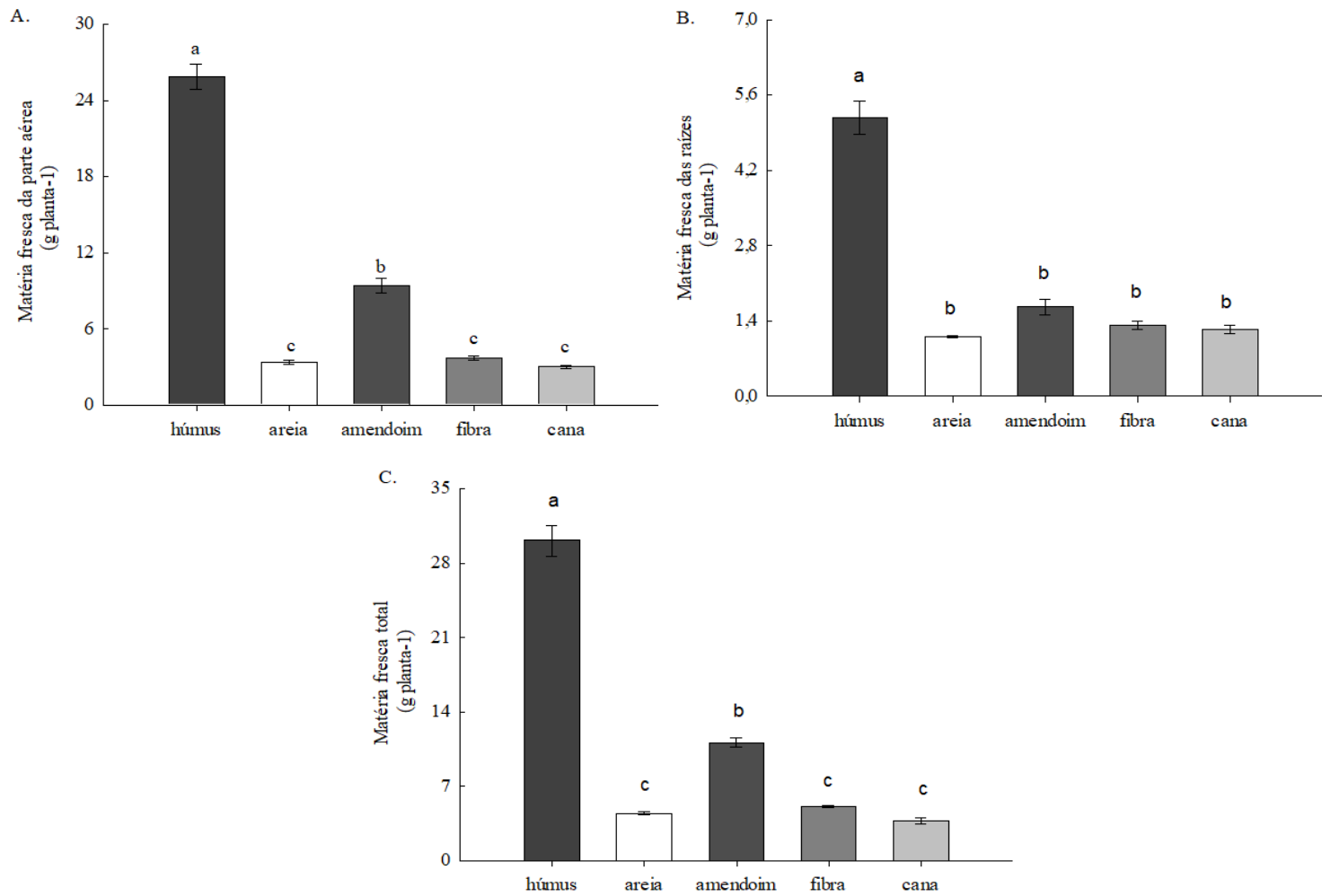

Figura 5. Matéria fresca da parte aérea (A), das raízes (B) e total (C) de plântulas de mamona submetidas a diferentes substratos contendo resíduos agroindustriais aos 28 dias após a semeadura. Diferentes letras indicam diferenças significativas ao tipo de substrato de acordo com o teste de Tukey $(P \leq 0,05)$.

Para a matéria seca da parte aérea, da raiz e total (Figura 6), o comportamento mostrou-se semelhante ao da matéria fresca, sendo também mais elevados nos tratamentos húmus e casca de amendoim. Para o tratamento contendo húmus observou-se um incremento em relação ao areia 
de $522 \%$ para a parte aérea, $427 \%$ para as raízes e $444 \%$ para a matéria seca total. Com relação ao tratamento amendoim, os incrementos para foram de 89,82 e $92 \%$, respectivamente.
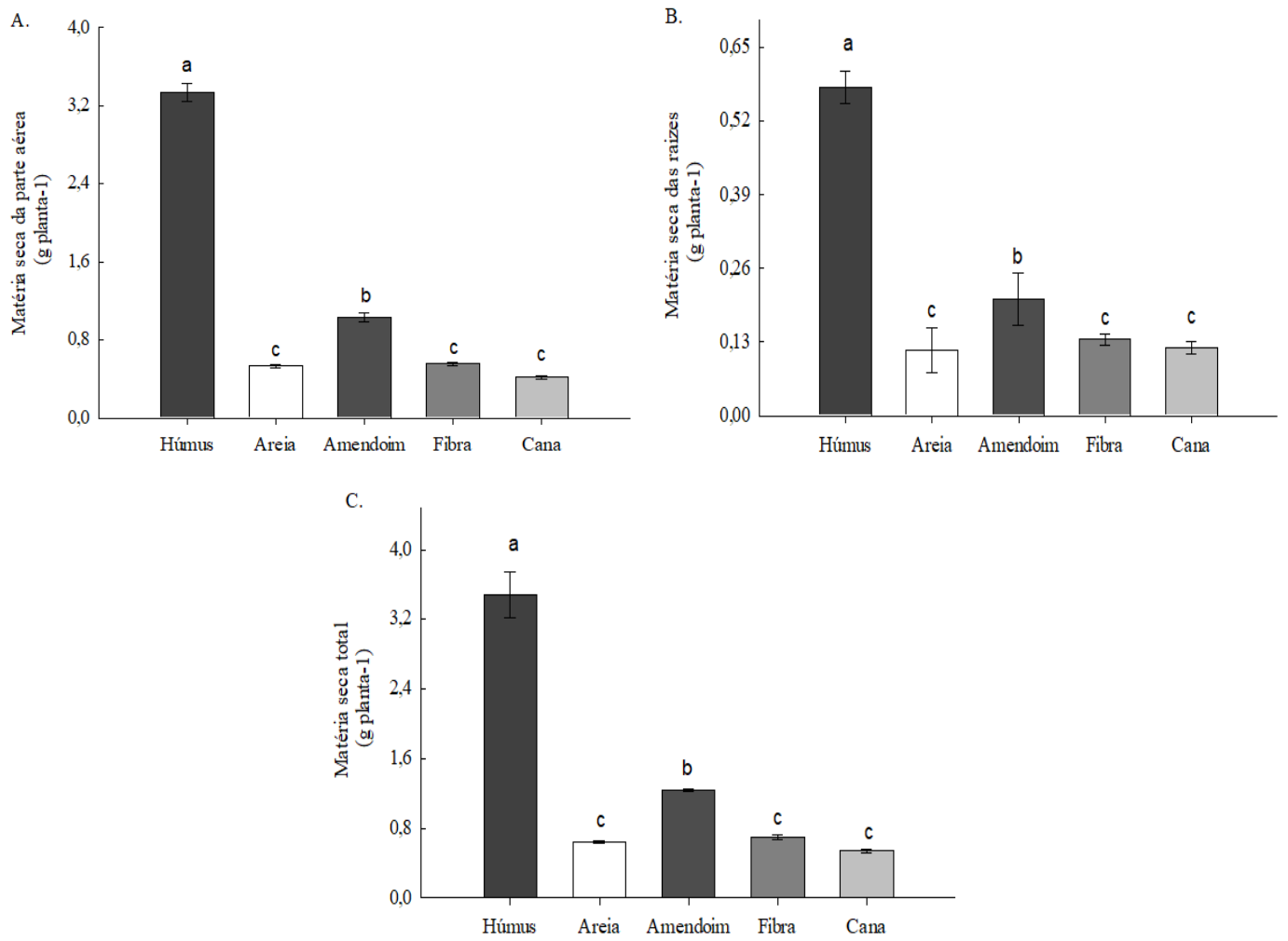

Figura 6. Matéria seca da parte aérea (A), das raízes (B) e total (C) de plântulas de mamona submetidas a diferentes substratos contendo resíduos agroindustriais aos 28 dias após a semeadura. Diferentes letras indicam diferenças significativas ao tipo de substrato de acordo com o teste de Tukey $(P \leq 0,05$

Os dados de matéria seca da parte área, da raiz e total, corroboraram com os resultados obtidos por Lima et al. (2006), onde os substratos contendo casca de amendoim apresentaram valores mais elevados do que os demais tratamentos, como a mucilagem de sisal e o bagaço de cana.

No presente trabalho, a fibra de coco não se mostrou um substrato adequado para o cultivo de plântulas de mamona. Os baixos valores de altura encontrados nas plântulas cultivadas em substrato contendo fibra de coco, corroboram com os dados de Costa et al. (2007), onde os autores testaram o uso da fibra de coco e do resíduo de algodão para a composição de substratos para plântulas de tomateiro e observaram que fibra de coco inibiu o crescimento. Acredita-se que a fibra de coco não proporcionou condições adequadas de aeração e suprimento de nutrientes para as plantas devido à lenta decomposição e liberação de nutrientes. Semelhantemente à fibra de coco, a utilização de bagaço de cana não se mostrou adequada para o cultivo de plântulas de mamona. De acordo com Gomes e Silva (2004) os substratos contendo bagaço de cana não são adequados para o crescimento da mamoneira, devido à elevada razão $\mathrm{C} / \mathrm{N}$, o que pode ter ocasionado deficiência nutricional de Nitrogênio. 


\section{CONCLUSÃO}

Devido ao reduzido custo e fornecer uma destinação adequada ao resíduo, o uso da casca de amendoim poderia ser uma alternativa orgânica para o cultivo de mamona, visto ser uma estratégia viável e ambientalmente vantajosa.

\section{REFERÊNCIAS}

ALMEIDA, J. D. P. (2010). Biodiesel o "óleo filosofal": desafios para a educação ambiental no caldeirão do "desenvolvimento sustentável".

ALMEIDA, M. J. (2017). Reposição deficitária de água e adubação com organomineral no crescimento e produção de tomateiro industrial (Dissertação e doutorado), Instituto Federal de Educação.

ANDRADE NETO, C. O. D., MELO FILHO, C. P., MOURA, L. R. B., MIRANDA, R. J. A., PEREIRA, M. G., MELO, H. N. S., \& LUCAS FILHO, M. (2002). Hidroponia com esgoto tratado-forragem hidropônica de milho. Simpósio Ítalo-Brasileiro de Engenharia Sanitária e Ambiental, 6.

CAVALCANTI, N. B.; RESENDE, G. M.; BRITO, L. T. L. (2002). Emergência e crescimento do imbuzeiro (Spondias tuberosa Arr. Cam.) em diferentes substratos. Revista Ceres, 49(282), 97-108.

CORWIN, D. L., \& LESCH, S. M. (2005). Apparent soil electrical conductivity measurements in agriculture. Computers and electronics in agriculture, 46(1-3), 11-43.

COSTA, C. A., RAMOS, S. J., SAMPAIO, R. A., GUILHERME, D. O., \& ARNALDO, L. (2007). Fibra de coco e resíduo de algodão para substrato de mudas de tomateiro. Horticultura Brasileira, 25(3), 387391.

DANNER, M. A., CITADIN, I., FERNANDES JUNIOR, A. D. A., ASSMANN, A. P., MAZARO, S. M., \& SASSO, S. A. Z. (2007). Formação de mudas de jabuticabeira (Plinia sp.) em diferentes substratos e tamanhos de recipientes. Revista Brasileira de Fruticultura, 29(1), 179-182.

GODOY, L. J. G. D., SANTOS, T. D. S., VILLAS BÔAS, R. L., \& LEITE JÚNIOR, J. B. (2008). Índice relativo de clorofila e o estado nutricional em nitrogênio durante o ciclo do cafeeiro fertirrigado. Revista Brasileira de Ciência do Solo, 32, 217-226.

GOMES, J. M.; SILVA, A. R. OS SUBSTRATOS E SUA INFLUÊNCIA NA QUALIDADE DE MUDAS. IN: BARBOSA, J. G.; MARTINEZ, H. E. P.; PEDROSA, M. W. \& SEDIYAMA, M. A. N. (2004) Nutrição e adubação de plantas cultivadas em substratos. Viçosa: UFV, 190-225.

HIGASHIKAWA, F. S. (2013) Resíduos Orgânicos e Solos: formulação, índices de maturação de substratos e compostos orgânicos voláteis alvos. Tese de doutorado. Universidade Federal de Lavras, Lavras, MG, Brasil.

LIMA, R. D. L. S. D., SEVERINO, L. S., SILVA, M. I. D. L., VALE, L. S. D., \& BELTRÃO, N. E. D. M. (2006). Volume de recipientes e composição de substratos para produção de mudas de mamoneira. Ciência e Agrotecnologia, 30, 480-486. 
LIRA, M. A., \& BARRETO, F. P. (2009). Oleaginosas com fonte de matéria-prima para a produção de biodiesel. Natal: EMPARN.

MARTINEZ, H.E.P. O uso de cultivo hidropônico de plantas em pesquisa.Viçosa: UFV, 2002. 61p.

MALHEIROS, S., \& PAULA JÚNIOR, D. R. (1997). Utilização do processo de compostagem com resíduos agroindustriais. In CONGRESSO BRASILEIRO DE CIÊNCIA DO SOLO (Vol. 26).

MElO, A., BRITO, M., GOIS, M., BARRetO, M., VIEGAS, P., \& HOLANDA, F. (2003). Efeito de substratos orgânicos organo-minerais na formação de mudas de maracujazeiro (Passiflora edulis). Revista Científica Rural, 8(2), 116-121.

MENDES, A. M. S. (2007). Introdução à fertilidade do solo. Recuperado em 05 junho,2017 de https://ainfo.cnptia.embrapa.br/digital/bitstream/CPATSA/35800/1/OPB1291.pdf

MONTEIRO, J. E. B. A., SENTELHAS, P. C., CHIAVEGATO, E. J., GUISELINI, C., SANTIAGO, A. V., \& PRELA, A. (2005). Estimação da área foliar do algodoeiro por meio de dimensões e massa das folhas. Bragantia, 64(1), 15-24.

SEVERINO, L. S., FERREIRA, G. B., MORAES, C. R. de A., GONDIM, T. M. S., FREIRE, W. S. A., CASTRO, D. A., CARDOSO, G. D. \& BELTRÃO, N. E. M. (2006). Crescimento e produtividade da mamoneira adubada com macronutrientes e micronutrientes. Pesquisa Agropecuária Brasileira, 41(4), $563-$ 568.

SILVA, J. D. (2017) Faixas de condutividade elétrica no desenvolvimento e características físicoquímicas de pimentão pé-franco e enxertado. Dissertação (Mestrado). Faculdade de Ciências Agronômicas da Unesp, Botucatu, SP, Brasil.

SILVA, P. C. C., DO COUTO, J. L., \& DOS SANTOS, A. R. (2010). Efeito dos íons amônio e nitrato no desenvolvimento do girassol em solução nutritiva. Revista da FZVA, 17(1), 104-114.

SOARES, F. C., MELLO, R. P., PEITER, M. X., BElLE, R. A., DIAS ROBAINA, A., APARECIDA VIVAN, G., \& PARIZI, A. R. C. (2012). Consumo de água pela cultura do lírio, cultivado em substratos alternativos em condições de ambiente protegido. Ciência Rural, 42(6), 1001-1006.

TORRES, A. J., BREGAGNOLI, M., MONTEIRO, J. M. C., \& CARVALHO, C. A. M. (2012). Emergência de plântulas de cafeeiro em substratos de borra de café. Revista Agrogeoambiental, 4(3). 